\title{
Visitando, pesquisando, aprendendo e brincando: uma revisão de atividades para o ensino informal de ciências
}

\begin{abstract}
Ana Paula Sebastiany
Michelle Camara Pizzato

José Cláudio Del Pino

Tania Denise Miskinis Salgado

Resumo

Este trabalho apresenta uma revisão acerca do papel do ensino informal em ciências. Dentre as discussões, está a diferenciação entre o ensino formal e o informal no que se refere à aprendizagem. Entre os resultados das pesquisas analisadas, destaca-se o fato de que os espaços de educação não formal são importantes complementos à escola. Verificou-se que as estratégias adotadas concebem estes espaços como locais de interação efetiva entre alunos, professores e monitores. O objetivo destas atividades, em geral, é a demonstração ou a simulação de fenômenos científicos. Finalmente, parece que as pesquisas em educação em ciências sobre ensino formal e informal buscam a compreensão de como as aprendizagens acontecem fora da escola com a intenção de construir um referencial teórico para essas práticas e processos de educação.

Palavras-chave: ensino e aprendizagem, contexto informal, educação em ciências

Abstract

Visiting, investigating, learning and playing: a review of activities for informal science education

This paper presents a review about the role of informal teaching in science. Among the discussions, distinction is presented between formal and informal education and its relationship with learning. The results of the surveys analyzed show that the spaces of non-formal education are important complements to the school. It was found that the strategies adopted conceive these spaces as places of effective interaction between students, teachers and monitors. The aim of these activities, in general, is a demonstration or simulation of scientific phenomena. Finally, it seems that research in science education on formal and informal education seeks an understanding of how learning happens outside the school with the intention of building a theoretical framework for these practices and education processes.
\end{abstract}

Keywords: teaching and learning, context informal, science education 


\section{Introdução}

Educar, entre outras coisas, significa criar formas de transcender os espaços ditos escolares, ir além da sala de aula. O saber-conhecer, o aprender, o fazer, o ser e o viver junto acontecem, também, através das experiências vividas, a partir das relações estabelecidas com o mundo. $O$ processo educativo ocorre em diferentes contextos, institucionalizados ou não, sob diversas modalidades e a partir da adoção de diferentes práticas e metodologias que valorizam a participação e interação dos sujeitos, e vem ganhando lugar de destaque na construção do conhecimento. Sendo assim, o presente trabalho tem por objetivo apresentar uma definição e caracterização para o ensino informal das ciências, assim como uma revisão bibliográfica sobre os tipos de atividades desenvolvidas nesse contexto de ensino e aprendizagem.

\section{Ensino formal, não formal ou informal?}

A educação, enquanto forma de ensino e aprendizagem, é adquirida ao longo da vida dos sujeitos e, segundo a literatura, pode ser dividida em três diferentes formas: educação escolar formal, educação não-formal e educação informal. De acordo com Cazelli e Vergara (2007) os autores de língua inglesa usam os termos informal science education e informal science learning para a educação em ciências que usualmente acontece em lugares como museus de ciência e tecnologia, science centers, zoológicos, jardins botânicos, no trabalho, em casa, entre outros. Já os de língua portuguesa subdividem a educação em ciências fora da escola em dois subgrupos: educação não-formal e informal. Nesse sentido, ao aprofundar a pesquisa sobre esses termos, verifica-se a existência de distintas definições apresentadas por pesquisadores da área. A seguir, são expostas algumas conclusões referentes a essas conceituações, com o propósito de contribuir para reflexões teóricas e empíricas sobre o tema, e então propor uma definição compatível com a compreensão sobre ensino informal para fins desse trabalho ${ }^{1}$.

Quanto ao ensino formal, existe consenso de que está ligado à instituição escolar, correspondendo a um modelo sistemático e organizado de ensino, estruturado segundo determinadas leis e normas e apresentando um currículo relativamente rígido em termos de objetivos, conteúdo e metodologia, com níveis, graus, programas, currículos e diplomas. No entanto, com relação à definição de não formal e informal, fica evidente a ausência de significado

\footnotetext{
${ }^{1}$ Esse trabalho trata de uma proposta vinculada a uma pesquisa de mestrado.
} 
fixo e uniforme e a falta de uma definição comum desses dois termos, sendo difícil traçar limites claros entre essas práticas.

Segundo Marandino et al. (2003):

"É possivel perceber que existe uma busca com objetivo de diferenciar os termos aqui em discussão, onde os critérios ultrapassem uma perspectiva meramente 'administrativa' e que caminhe para uma distinção conceitual. Contudo, verifica-se que diferentes práticas na área da educação formal, não formal e informal são, algumas vezes, colocadas na mesma categoria, evidenciando uma falta de consenso nesse aspecto. O tema da aprendizagem também entra no cenário da discussão como possível elemento diferenciador, assim como o currículo e o espaço físico, não sendo esses, entretanto, critérios consensuais para distinguir os termos em análise" (p. 7)

Assim, por exemplo, as atividades em museus, para autores como Cazelli (2000), Gohn (2006) e Chagas (1993), são um tipo de atividade que processa-se em contextos não-formais; já para autores como Falk (2001) apud Marandino et al. (2003), Wellington (2000) apud Soares (2004), Trilla (1993), Asensio (2001), Lucas (1983); Boekaerts e Minnaert (1999); Gerber, Marek e Cavallo (2001) e Gaspar (1993), esse tipo de atividade enquadra-se dentro de contextos informais.

Além disso, um dos aspectos destacados como diferenciador desses contextos é o espaço físico, embora, como aponta Smith (1996) apud Marandino et al. (2003), este tipo de classificação favoreça a sobreposição e confusão entre informal e não formal. Segundo Chagas (1993), alguns autores designam de informal qualquer tipo de aprendizagem que se processa fora do espaço escolar:

"A aprendizagem informal desenvolve-se no dia-a-dia do jovem através de conversas informais entre familiares, colegas e amigos, podendo ocorrer em qualquer lugar". Maarschalk (1988) apud Ferreira et al. (2003, p.1).

Nesse sentido, o que diferencia a aprendizagem informal da formal e não formal, seria que essa ação não possui uma intencionalidade educativa, não é estruturada, planejada e organizada, não há fixação de tempos e locais. Alguns exemplos podem ser encontrados nos trabalhos de Afonso, (1989) apud Benzaquen, (2007); Barzano, (2003); Yáñez e García, (2003); Cazelli, (2000). Tal concepção é coerente com a definição proposta por Wellington (2000) apud Soares (2004), de aprendizagem informal como um modo voluntário de aprendizagem, por vezes acidental, de puro acaso, não avaliável.

Seguindo essa mesma linha de pensamento, podemos citar algumas ideias de Gohn (2006). Essa autora acrescenta que na educação informal, os agentes educadores são os pais, a família em geral, os amigos, os vizinhos, colegas de escola, a igreja paroquial, os meios de comunicação de massa, entre outros. Para a autora, esse processo educativo é demarcado por referência de 
nacionalidade, localidade, idade, sexo, religião, etnia, entre outros, que opera em ambientes espontâneos, onde as relações sociais se desenvolvem segundo gostos, preferências, ou pertencimentos herdados. Os objetivos desse contexto são os de apenas socializar os indivíduos, desenvolver hábitos, atitudes, comportamentos, modos de pensar e de se expressar no uso da linguagem, segundo valores e crenças de grupos que se frequenta ou que se pertence por herança, desde o nascimento; ou seja, trata-se do processo de socialização dos indivíduos.

A autora menciona ainda que a educação informal é um processo permanente e não organizado: os conhecimentos não são sistematizados e são repassados a partir das práticas e experiência anteriores. Usualmente é o passado orientando o presente, atuando no campo das emoções e sentimentos. E por fim, os resultados não são esperados, eles simplesmente acontecem a partir do desenvolvimento do senso comum nos indivíduos, senso este que orienta suas formas de pensar e agir espontaneamente.

Diante do exposto, fica evidente que, em relação ao ensino de ciências, a educação informal ainda sofre restrições e gera inquietações. As mais comuns se referem à impossibilidade de ensinar e aprender ciências nesses ambientes. De acordo com Gaspar (2002), não é difícil compreender a razão de tais descrenças ou restrições, basta observar atentamente a visita de crianças a um centro de divulgação científica:

"Elas correm de um lado para o outro, fixam-se alguns instantes aqui e ali, riem, gritam, assustam-se, aborrecem-se, encantam-se, numa atividade incessante e quase sempre desordenada. Mesmo quando acompanhadas dos pais, professores ou em visitas monitoradas, a dispersão tende a ser muito grande, pois os estímulos são muitos, até mesmo onde se procura dar algum ordenamento lógico ou pedagógico às apresentações, o que não é freqüente". (p. 174)

Além disso, há o temor de que os sujeitos, inseridos nesse tipo de contexto de aprendizagem, possam desenvolver ideias que não são aceitas cientificamente, o que poderia impedir a construção do conhecimento concebido como "correto". Este temor está associado com a concepção de que as nossas ideias estariam "prontas e acabadas", ou seja, que as mesmas não sofrem modificações. Nesse sentido, Gaspar (2002) aponta uma contribuição importante, de que "não há ideias errôneas, porque não há ideias definitivas. Toda ideia é, ou pode ser, provisória, desde que adequadamente trabalhada".

Assim, é possível proporcionar aprendizado de conceitos, atitudes e procedimentos vinculados às ciências em instituições de ensino informal, uma vez que "a educação informal é um processo que se prolonga por toda nossa vida e no qual as pessoas adquirem e constroem conhecimentos, habilidades, atitudes e modos de discernimento mediante as experiências diárias e sua relação com o meio em que estão inseridos" (Trilla, 1993). Para Gaspar (1993), no contexto 
informal, ensino e aprendizagem ocorrem espontaneamente, sem que, na maioria das vezes, os próprios participantes do processo tenham consciência deles. Acontece na experiência do dia-adia, através de jornais, revistas, programas de rádio e televisão, em centros culturais, na visita a um museu, jardins botânicos, zoológico, centro de ciências, feiras, entre outros.

\section{Caracterização de Ensino informal}

Os dados obtidos até o presente momento reforçam a percepção da inexistência de uma diferenciação comum entre educação formal, não formal e informal tanto na bibliografia quanto entre os profissionais da área. Diante do exposto, torna-se necessário diferenciar os conceitos aqui abordados, buscando apresentar uma definição e caracterização para o ensino informal das ciências. Para tanto, escolhemos como referencial as discussões sobre contextos de aprendizagens desenvolvidas por Asensio (2001) nas quais esse autor apresenta uma proposta interessante para determinar os aspectos relevantes na distinção entre a aprendizagem em contextos formais e informais. Nessa proposta, existe um conjunto de variáveis que nos permitem analisar os resultados que se apresentam em ambos os casos de forma mais precisa. Estas variáveis estão relacionadas aos processos de ensino (como, por exemplo, os objetivos de aprendizagem, o conteúdo, a sequência do conteúdo - Quadro 1) e de aprendizagem (como, por exemplo, a motivação, a regulação da aprendizagem e a implicação emocional - Quadro 2).

Quadro 1: O planejamento do processo de ensino em contextos formais e informais (Asensio, 2001)

\begin{tabular}{|l|l|l|}
\hline & APRENDIZAGEM & APRENDIZAGEM \\
& EM CONTEXTOS & EM CONTEXTOS \\
& FORMAIS & INFORMAIS \\
\hline Objetivos & - curriculares & - extracurriculares \\
Conteúdos & - predeterminados (fechados) & - de livre escolha (abertos) \\
\hline Tipo de & $* * *$ conceituais & $*$ conceituais \\
conhecimento & $* *$ procedimentais & $* *$ procedimentais \\
& $*$ atitudinais & $* * *$ atitudinais \\
\hline Sequência dos & mais teórico & mais aplicado \\
\end{tabular}




\begin{tabular}{|l|l|l|} 
Conteúdos & - linear & - não linear \\
& - exógena & - endógena \\
\hline Tipo de atividade & - estáticas & - flexíveis \\
& - homogêneas & - diversificadas \\
\hline Avaliação da & - objetivo: produto & - objetivo: processo \\
- metodologia: quantitativa & - metodologia: qualitativa \\
& - avaliação: somativa & - avaliação: formativa \\
- somente individual & - individual, grupal e social \\
\hline
\end{tabular}

* pouco considerado; ${ }^{* *}$ razoavelmente considerado; ${ }^{* * *}$ muito considerado

Nos aspectos relativos ao planejamento de ensino, o autor destaca que as atividades formais costumam ser fechadas enquanto as informais tendem a ser abertas. Quando se inicia uma atividade, ela pode ser realizada em vários lugares e de diversas maneiras, os alunos têm a sensação de controle, ou seja, são os alunos que decidem os passos seguidos para a realização da atividade. Neste caso, o controle é apenas uma ilusão, já que nos programas informais tudo deve ser planejado. Mas o fato de que os alunos tenham essa ilusão de controle é fundamental para que se sintam agentes do seu próprio processo de aprendizagem e, assim, estimular a sua motivação e seu envolvimento emocional.

Os objetivos de aprendizagem diferem em ambos os casos, pois em contextos formais estes seguem um critério curricular - ligado ao currículo escolar e às disciplinas -, prédeterminado e fechado pelas instituições e centros educativos. No entanto, em contextos informais os critérios não são pré-determinados, mas variam em relação aos centros ou museus, com propostas abertas e extracurriculares, ao estarem vinculadas à lógica da atividade ou situação problema (problema concreto), nas quais o visitante ou o público em geral têm a possibilidade de escolha sobre seus próprios objetivos.

A sequência dos conteúdos, no caso do contexto formal, se caracteriza de forma linear, comum para todos os alunos e determinada externamente (exógena). O desenvolvimento dos conteúdos costuma seguir a estrutura da disciplina de referência. Para o contexto informal, a sequência de aprendizagem segue a dinâmica da própria atividade ou problema proposto. Isto faz com que as sequências dos programas informais sejam multidisciplinares, através das quais podese realizar diferentes caminhos de aprendizagem (aberta), e o sujeito pode determinar a sequência (endógena), o que the dá mais poder e permite que se aproprie melhor à realidade. A sensação que o aluno tem, no contexto formal, é que a lógica da atividade sempre está marcada pelo livro ou pelo professor, enquanto, no contexto informal, a lógica é definida pelo que os 
próprios alunos consideram necessário para o desenvolvimento da atividade ou resolução do problema proposto, o que também os leva a escolher sobre os próximos conteúdos ou atividades (isto é o que cria a ilusão de aprendizagem orientada pelo aluno, quando, na verdade, em escassas ocasiões, foge-se do roteiro).

A seleção dos conteúdos e a forma de trabalhá-los é resultado do exposto anteriormente. No contexto formal os conhecimentos são tratados como prontos e acabados, e tendem a ser muito mais teóricos, enquanto no contexto informal se propõe construí-los (e, portanto discutilos), e estes costumam estar mais orientados para um conhecimento contextualizado e aplicado. Sendo assim, o fato de que nos programas formais os conhecimentos sejam mais teóricos e já estejam prontos e completos implica que os conteúdos conceituais, entendidos como produtos finais, sejam mais considerados se comparados com os procedimentos e as atitudes. Por outro lado, com relação aos conhecimentos, o aplicado e a ser construído do contexto informal dá mais importância para a metodologia e ideologia com a qual os construímos. Assim apresenta uma maior incidência sobre as atitudes e os procedimentos que sobre os conteúdos conceituais - ou seja, põe-se mais ênfase no processo de construção e interpretação do conhecimento - (Asensio, 1994; Asensio e Pol, 1999). Além disso, quanto à diversificação das atividades de cada programa, nos programas informais existe uma convicção e uma vontade por propor atividades flexíveis/mutáveis e diversificadas, que prendam a curiosidade e o interesse de seus participantes, e abandonar conscientemente a homogeneidade da aprendizagem no contexto formal.

$\mathrm{Na}$ avaliação, há diferenças importantes com respeito aos objetivos, à metodologia e às características comuns aos estudos de ambos os contextos de aprendizagem. No contexto formal, os objetivos estão baseados nos resultados finais, a metodologia é mais quantitativa e a valoração de resultados é somativa, e quase sempre individual. No contexto informal, os objetivos são mais aplicados, formativos e focados no processo de investigação que o aluno realiza. Utiliza-se uma metodologia qualitativa e os resultados do grupo são mais considerados do que os individuais.

No que se refere ao planejamento do processo de aprendizagem, Asensio (2001) comenta já foram apresentados muitos indicadores. Nos últimos anos, criticou-se a escassa conexão estabelecida na aprendizagem em contextos formais com o conhecimento prévio dos alunos, pois na maioria das vezes as aprendizagens são propostas sem explicitar as ideias ou teorias prévias que os alunos têm sobre os conteúdos trabalhados. Como mencionado anteriormente, os contextos informais sempre procuram vincular-se com os conhecimentos e interesses dos alunos. Além disso, no contexto formal, os conhecimentos costumam ser trabalhados de forma compartimentada e fechada, isolados uns dos outros. Em geral, quando um determinado conteúdo é finalizado parte-se para outro distinto sem uma continuidade, enquanto que os programas informais insistem na aplicabilidade, dinamismo e relação entre os conhecimentos. 
Quadro 2: O planejamento do processo de aprendizagem em contextos formais e informais (Asensio, 2001)

\begin{tabular}{|c|c|c|}
\hline & $\begin{array}{l}\text { APRENDIZAGEM } \\
\text { EM CONTEXTOS } \\
\text { FORMAIS }\end{array}$ & $\begin{array}{l}\text { APRENDIZAGEM } \\
\text { EM CONTEXTOS } \\
\text { INFORMAIS }\end{array}$ \\
\hline Ativação do conhecimento & $\begin{array}{l}\text { - escassa conexão com o } \\
\text { conhecimento prévio } \\
\text { - concepções pessoais implícitas } \\
\text { - conhecimento estanque e inerte }\end{array}$ & $\begin{array}{l}\text { - maior conexão com o } \\
\text { conhecimento prévio } \\
\text { - concepções pessoais explícitas } \\
\text { - conhecimento relacionável e } \\
\text { aplicado }\end{array}$ \\
\hline Contextualização & $\begin{array}{l}\text { - descontextualizado da vida } \\
\text { cotidiana e dos conhecimentos } \\
\text { sociais significativos }\end{array}$ & $\begin{array}{l}\text { - contextualizado na vida } \\
\text { cotidiana e nos conhecimentos } \\
\text { sociais significativos }\end{array}$ \\
\hline Motivação & $\begin{array}{l}\text { - extrínseca não contingente } \\
\text { - não explora a curiosidade } \\
\text { nem os interesses }\end{array}$ & $\begin{array}{l}\text { - intrínseca e extrínseca } \\
\text { contingente } \\
\text { - baseada na curiosidade } \\
\text { e interesses }\end{array}$ \\
\hline Regulação & - externa (dirigida pelo professor) & $\begin{array}{l}\text { - interna (dirigida pelos alunos por } \\
\text { consenso) }\end{array}$ \\
\hline Interação & $\begin{array}{l}\text { predomina uma } \\
\text { aprendizagem individual }\end{array}$ & $\begin{array}{l}\text { ocorrem aprendizagens de caráter } \\
\text { individual, grupal e social }\end{array}$ \\
\hline Implicação emocional & $\begin{array}{l}\text { - conteúdos "frios" } \\
\text { - escassa utilização emocional }\end{array}$ & $\begin{array}{l}\text { - conteúdos “quentes" } \\
\text { - alta utilização afetiva-emocional }\end{array}$ \\
\hline Tomada de consciência & - não é provocada e é escassa & - é buscada de modo direto \\
\hline Comunicação & $\begin{array}{l}\text { - escassos produtos de } \\
\text { comunicabilidade }\end{array}$ & $\begin{array}{l}\text { - diversificação de produtos } \\
\text { comunicáveis }\end{array}$ \\
\hline
\end{tabular}


O ambiente de aprendizagem do contexto formal ocorre na escola, enquanto no contexto informal há diferentes espaços, como os museus, os centros de ciência ou os programas e meios de comunicação, entre outros. A característica dos programas formais é que são realizados no centro educativo, geralmente sem contextualização dos conteúdos, diferentemente do informal, que apresenta maiores oportunidades em aproximar os conteúdos ao seu contexto real e à experiência com objetos e situações próximas, nas quais se proporciona o conhecimento. As características comuns aos contextos informais, e que apresentam aspectos cruciais para o planejamento de situações de aprendizagem mais atraentes e efetivas, são que o processo de aprendizagem é motivado e regulado pelo próprio sujeito, e condicionado ao uso decisivo dos aspectos motivacionais e emocionais, contrariamente ao que ocorre no processo de aprendizagem em contextos formais.

Além disso, a aprendizagem no contexto formal é considerada como um processo individual. As aprendizagens em contextos informais incluem espaços de negociação dos significados e a interação entre os sujeitos. As discussões como estratégia de trabalho em pequenos grupos, as apresentações dos resultados ao grande grupo e à família e a comunicabilidade dos resultados através de exposições com impacto social são ferramentas que permitem trabalhar em cooperação, mas que também proporcionam a tomada de consciência dos conhecimentos construídos. As atividades de reflexão sobre a própria aprendizagem são necessárias para que os alunos se tornem conscientes das suas próprias estratégias de aprendizagem, tanto as de tipo genérico, como as mais específicas. As aprendizagens nos programas informais costumam persistir nos resultados como uma maneira de definir objetivos finais de aprendizagem, através de uma atividade que simbolize os resultados alcançados, mas também como uma ferramenta construída tanto no plano individual como em grupo e que pode ser apresentada aos outros, sejam seus colegas, seus professores, sua família, seus vizinhos ou colegas usuários de internet do outro lado do mundo.

Com relação ao descrito até o momento, uma conclusão importante deste autor diz respeito às definições sobre o contexto informal, pois essas são confundidas entre o espaço de aplicação e as propostas que orientam o processo de aprendizagem. Há, portanto, uma tendência à consideração ilícita do contexto, entendido em seu sentido físico como variável fundamental diferenciadora entre o formal e o informal, de maneira que a sala de aula entendida como espaço fechado e disciplinar simularia perfeitamente o contexto formal, enquanto os espaços abertos, externos ao ambiente escolar, exemplificariam a área de aplicação do contexto informal. Outra conclusão é que o contexto informal diferencia-se do formal no sentido de que a aprendizagem não é vista como o único objetivo que deve orientar a atividade, mas sim que esta se inclui num contínuo de lazer ou turismo cultural que modifica sensivelmente a proposta e seus ritmos.

Entretanto, na análise dos objetivos e dos resultados da aprendizagem, em ambos os contextos, o autor aponta uma contradição significativa. O objetivo prioritário dos contextos 
informais não é necessariamente a aprendizagem, tal e como a entendemos em contextos formais, isto é, como um processo de mudança conceitual forte. No entanto, em determinados casos os resultados mostram de que no museu se pode desenvolver uma reestruturação ou mudança forte nas estruturas cognitivas. Encontramo-nos aqui com um paradoxo da aprendizagem, uma diferença entre os objetivos e os resultados da aprendizagem em cada um dos contextos, o formal e o informal. Em Asensio (2001) pode-se encontrar a discussão sobre o paradoxo da aprendizagem informal: o ensino formal tem como objetivo prioritário a aprendizagem (e, portanto, a mudança conceitual) e em muitas ocasiões não a atinge, enquanto o ensino informal, que não tem como objetivo prioritário a aprendizagem, consegue em muitas ocasiões melhores resultados.

Por fim, o autor sugere que os contextos de aprendizagens informais (e também os formais) devem levar em conta que a aprendizagem é um processo cada vez mais complexo, e, portanto, não pode esgotar-se somente em um de seus aspectos, por mais importante que seja - todo o programa deve ser planejado tendo em conta a inclusão de todos os processos básicos implicados numa situação de aprendizagem.

\section{Atividades de Ensino Informal}

Partindo dessas reflexões, acredita-se que a educação em ciências deveria repensar a ideia da escola como o único espaço educativo (Pérez e Moliní, 2004). Afinal, a importância das fontes informais está relacionada com os grandes objetivos preconizados no ensino das ciências e com a noção de que embora a escola seja fundamental, ela é, todavia, limitada, pois é temporária, enfatiza aprendizagens que se desatualizam facilmente, e não é exclusiva na vida social de um indivíduo (Canavarro, 1999 apud Soares, 2004). Como realça este autor, não podemos esquecer que a educação decorre ao longo da vida e que deve ser um processo dinâmico, que acompanha o indivíduo ao longo da sua existência, permitindo-Ihe acompanhar o desenvolvimento progressivo do conhecimento, as inovações tecnológicas e a mobilidade social a que se está sujeito no mundo atual.

A aprendizagem nos museus e centros de ciência interativos é vista, de maneira quase consensual, como um processo marcado por uma enorme liberdade em que o visitante pode movimentar-se circulando pelos espaços, movido apenas pelo seu desejo e curiosidade (Colinvaux, 2005). Isto porque, ao contrário da instituição escolar, os museus e centros de ciência não têm de lidar com processos de avaliação, e com imperativos de transmissão de conhecimentos - estes deverão entender a aprendizagem mais como um processo do que como um produto (Faria, 2001). 
Este tipo de atividade permite que a aprendizagem do aluno aconteça de um modo natural, isto é, que a aprendizagem seja orientada por seu interesse e curiosidade. Para que isso se torne possível é essencial que as atividades sejam cuidadosamente planejadas e que os alunos se envolvam, sempre que possível, na identificação, formulação e resolução de problemas, que incluam atividades de observação, experimentação, registro e atividade reflexiva (Freitas,1999 apud Ribeiro, 2005).

Além disso, os museus podem contribuir para a formação científica dos jovens de uma forma que a escola usualmente não oferece. Os museus desempenham assim, segundo Proctor (1973) apud Chagas (1993), uma dupla função, que consiste em estimular a curiosidade do visitante e em despertar-lhe o gosto pela investigação pessoal, seguindo metodologias próprias que utilizam montagens científicas de diversos tipos e recorrendo a meios audiovisuais de variados níveis de sofisticação. Além disso, a exposição científica ampla, interativa, capaz de criar um ambiente rico de estímulos e interações sociais, são aspectos que na opinião de Semper (1990) e Diamond (1986) são os mais promissores em termos de aprendizagem informal de ciências.

"Um povo culto não é aquele que passa apenas algumas horas diárias numa sala de aula, via de regra despojada de qualquer outro equipamento que não carteiras e quadro-negro. É necessário que ele viva num ambiente permeado de estímulos culturais, que no pátio de sua escola, nas ruas e praças de sua cidade ele se encontre com a história e as conquistas de seus semelhantes e, nesse sentido, a contribuição de instituições como os centros de ciências nos parece indispensável". (Gaspar, 1992, p. 162)

No decurso das visitas os alunos podem observar, selecionar, analisar, simular, manipular, experimentar e desenhar, utilizando uma multiplicidade de recursos: modelos, réplicas, meios audiovisuais, equipamento informático, material impresso (textos, ilustrações). Paralelamente, são desenvolvidas outras atividades: oficinas de trabalho, conferências, mesas redondas, cursos de formação, entre outras.

No âmbito dos conhecimentos procedimentais, os museus com estas características, contribuem para o desenvolvimento de habilidades manipulativas, destrezas manuais, coordenação motora e visual, entre outros. Porém, talvez seja no domínio afetivo onde têm maior influência (Cuesta et al., 2000). Nesse sentido, estes ambientes compreendem o desenvolvimento de interesses relacionados com a motivação, o desejo de aprender, a criatividade, enfim, valores importantes para a aprendizagem, tanto formal como informal, e que não são considerados, ou são menos explícitos, no ensino formal. 


\section{Complementar a escola}

Mesmo tendo reconhecido valor por parte de especialistas em Ensino de Ciências, as pesquisas realizadas nesses contextos de aprendizagem apontam que os espaços fora do ambiente escolar - centros e feiras de ciências, museus - são utilizados como recursos pedagógicos complementares às carências da escola - como, por exemplo, a falta de infraestrutura física e recursos pedagógicos que permitam um ensino experimental das ciências -, além de contribuir para o desenvolvimento de uma aprendizagem significativa, na medida que, na escola, os professores poderiam rever o conteúdo inicialmente abordado em exposições, vinculando o ensino formal com o informal (Vieira, Bianconi e Dias, 2005; Corsini e Araújo, 2007). Outros autores, como Gaspar (1993); Pérez e Moliní (2004); Oliveira e Moura (2005); Santos e Matela (2005); e Pinto (2007), também apontam que a educação formal, escolar, tem sido complementada ou acrescida de uma educação não-formal e informal, extraescolar, que tem de certa forma oferecido à sociedade o que a escola não oferece.

\section{Integrando museu e escola}

Nesse sentido, uma prática que vem crescendo nos últimos anos são as ações desenvolvidas entre museu e escola, as quais buscam promover a divulgação em ciências por meio da integração de espaços formais (escola) e não formais e informais (museus, centros de ciências, entre outros), sob forma de aula, de recursos didáticos exploradores da visita na (re)construção e consolidação dos conhecimentos dos alunos.

Segundo os autores citados, as visitas de estudo a museus e centros de ciência aumentam e enriquecem os currículos escolares. Através delas, os estudantes podem aprender mais e melhor ciência (Price e Hein, 1991 e Ferreira et al., 2003). No entanto, investigadores como Guisasola et al. (2005) questionam a utilização desse tipo de atividades exploradoras - isto é, atividades pós-visita aplicadas em situação formal -, defendendo a necessidade de planejar materiais para visitas a museus, que integrem os diferentes contextos de aprendizagem e que estimulem o interesse e a curiosidade dos estudantes, a fim de promover uma aprendizagem mais autônoma mediante trabalho de grupo orientado pelo professor.

Nesse sentido, Allard e Boucher (1991) apud Pérez e Moliní (2004), desenvolveram um modelo de utilização dos museus com fins educativos, potenciando a colaboração entre a escola e o museu. É um modelo baseado num enfoque do objeto museográfico desde três perspectivas (interrogação, observação e apropriação) articuladas num processo de investigação (formulação de questões, coleta de dados, análises e sínteses) que são realizadas em três etapas sucessivas 
(preparação, realização e prolongamento/continuidade) correspondentes a três momentos diferentes (antes, durante e depois da visita ao museu) e em dois espaços (escola e museu). Segundo Pérez e Moliní (2004), a grande vantagem deste modelo reside na união do museu e da escola em um mesmo processo pedagógico, ou seja, não opõe as duas instituições, mas as reúne.

Outro exemplo de integração museu-escola é o projeto interdisciplinar de Oliveira e Moura (2005), o qual foi desenvolvido em uma viagem de trem ao litoral do Espírito Santo. A intenção era explorar dois ambientes informais de aprendizagem (a estrada de ferro e suas paisagens físicas, humanas, sociais e o ecossistema marinho) para o desenvolvimento de conteúdos de duas disciplinas (Biologia e Geografia), complementando o espaço formal - a escola - e interagindo com ele para um melhor trabalho educativo. De acordo com os autores, nesses dois ambientes, pôde-se constatar um alto índice de interesse e de absorção do conhecimento de forma lúdica e eficiente. Concluíram ser possível aprimorar a fonte de conhecimentos para os estudantes, levando-os para a realidade local, redirecionando-os de uma condição de mero espectador em um conhecimento abstrato para um ator que está interagindo com a condição do conhecimento real.

Por último, podemos citar o estudo de Santos e Matela (2005), que procurou identificar se os museus são auxiliares para os professores, no processo de ensino e aprendizagem, e se as visitas a museus de ciência ajudam ao ensino das ciências e à compreensão por parte dos alunos de conceitos e procedimentos científicos. $\mathrm{O}$ estudo foi realizado em um museu interativo, que apresentava uma grande diversidade de módulos. Os autores destacam que é importante que o professor utilize estes meios para explorar as concepções dos alunos, traçando o caminho para de uma série de atividades, tais como: exibição de filme/documentário; percorrer o acervo do museu, acompanhado de um monitor; participação nos experimentos interativos (Viana, et al., 2009). Assim, os alunos são incentivados a explorar os espaços com autonomia e liberdade, fazendo suas escolhas sobre os objetos ou modelos que desejam manipular, sobre as informações que queiram ou não aprofundar, sobre a forma de disposição dos grupos no espaço físico, entre outros. Segundo Marandino (2001), os alunos, ao interagirem em pequenos grupos, trocam experiências, fazem tentativas e comentários sobre o ocorrido, confrontam informações, discordam ou se questionam, provocando uns aos outros, tendo como mediador dessas relações os objetos e modelos das exposições.

Essa integração entre diferentes contextos, segundo Ferreira et al. (2003), promove o interesse (gosto) e a aprendizagem das Ciências Naturais - os alunos aprendem quando realizam atividades diversificadas, significativas e familiares, por estarem relacionadas ao seu cotidiano. Estas atividades, baseadas em estratégias centradas no aluno, envolvem abordagens práticas e investigativas, simulações, visitas de estudo e saídas de campo, algumas delas implicando o contato direto dos alunos com a comunidade. 
Um exemplo disso é o trabalho de Freitas e Martins (2005), que realizaram uma visita de estudo a um Planetário, com o objetivo de identificar se esse espaço de aprendizagem contribui para que os alunos envolvidos (re)construam as suas concepções sobre uma temática específica, qual o impacto dessa visita na motivação desses alunos e qual a importância da utilização, em sala chegarem a conceitos, complementando os trabalhos de sala de aula com as visitas a centros de ciência.

Sendo assim, concorda-se com Pinto (2007), que o elevado potencial científico-pedagógico destas instituições deve ser aproveitado pelos agentes educativos como instrumento privilegiado de complemento curricular, incluindo-os explicitamente na prática educativa, na planificação e implementação das suas atividades didáticas, tanto em direta relação com os conteúdos programáticos, como numa perspectiva interdisciplinar e de enriquecimento pessoal dos alunos.

\section{Atendimento escolar}

Outro tipo de prática são as que ocorrem em um museu de ciências com a interação entre alunos, professores e monitores, conhecida por atendimento escolar. Segundo Rocha (2007), esses ambientes têm o desafio de trabalhar conceitos de forma crítica, estimular o debate e não transformar a visita ao museu em mais uma "aula" como ocorre no ambiente escolar. As atividades realizadas neste tipo de museu propiciam uma interação didático-pedagógica entre este público e o acervo do museu, com apoio e monitoria de professores e estudantes que compõem um corpo de trabalho na atividade de mediação. Essa mediação torna o espaço expositivo em um ambiente de diálogo, confronto de ideias, momento de reflexão e, longe de objetivar a reprodução das aulas de educação formal, procura dialogar com o visitante a fim de que suas concepções a respeito dos temas sejam levadas em consideração. Dentre as atividades, existem experimentos demonstrativos e interativos, além da visita dialogada, em que se dá o contato com acervos de objetos reais e de simulações audiovisuais, que procuram reproduzir fenômenos naturais e tecnológicos.

Gaspar (1993) desenvolveu um amplo espectro de atividades em um centro interdisciplinar de ciências, tais como: demonstrações e experiências realizadas pelo centro; demonstrações e experiências realizadas pelos visitantes (professores, alunos e população em geral); elaboração e empréstimo de material experimental (kits) para realização de demonstrações e experiências fora do centro; criação de pequenos viveiros; infraestrutura de apoio (equipamentos, material, textos, entre outros) a professores e alunos para realização de projetos e pesquisas; promoção de exposições e feiras de ciências; promoção de cursos de caráter introdutório aos mais variados ramos da ciência (eletrônica, computação, astronomia, entre outras); consulta e empréstimo de livros, revistas; exibição de filmes, slides, e outros. Para o autor, as atividades que pareciam mais importantes eram aquelas que envolviam direta ou 
indiretamente os professores de ciências. Acreditava que um centro de ciências localizado junto às escolas, a professores e alunos, levando recursos, apoio, assessoria e motivação, poderia estimular e até mesmo estabelecer a prática da experimentação como procedimento didático rotineiro nessas escolas. Sendo assim, as instalações do centro eram oferecidas para realização de visitas, trabalhos em grupo, realização de projetos e apoio ao professor no planejamento, preparação de aulas experimentais, empréstimos de equipamento, entre outros.

No entanto, a resposta a essa iniciativa foi pequena, devido à ausência dos professores. $\mathrm{O}$ pesquisador procurou, então, ir ao encontro destes, realizando um programa de visitas às escolas, levando parte do equipamento e montando uma pequena exposição por um dia. A situação, porém pouco se alterou: o professor continuou a não utilizar as instalações do centro para o desempenho do seu trabalho. Em relação a atividades extraescolares, entretanto, a situação era diferente. A presença do pesquisador era solicitada em todas as feiras de ciências, tanto diretamente, através dos próprios experimentos, como indiretamente, através do auxílio na construção de montagens experimentais. As visitas de classes ao centro eram sempre solicitadas, e muitos alunos visitavam-no em grupos, por recomendação de seus professores, mas com uma agenda livre para ver o que quisessem, sem qualquer cobrança. Isto levou, gradativamente, a uma reformulação da exposição: de montagens planejadas, dirigidas a atividades experimentais, ligadas aos programas escolares de ciências, para outras voltadas mais ao lúdico e motivacional. Percebeu-se que o aluno que visitava o centro não queria encontrar ali uma continuação de sua escola, mas aquilo que a escola não podia oferecer, tanto na forma como no conteúdo. Aos poucos, o objetivo de influir no ensino escolar, induzindo direta ou indiretamente os professores a desenvolver uma prática experimental em suas aulas de ciências, foi sendo deixado de lado, em favor de uma postura extraescolar. Ou seja, o perfil do ambiente já era outro: centrado na exposição, assumia um caráter de instituição extraescolar voltada à educação informal.

\section{Visitas agendadas e orientadas}

Seguindo nessa mesma perspectiva, de complemento ao ensino formal, podemos citar as visitas orientadas - visando à motivação e ao aprendizado de conceitos básicos de ciências -, as quais são realizadas com maior frequência e se constituem de três momentos: aquele que antecede a chegada, a visita e retorno à sala de aula. De acordo com Colombo Jr., Aroca e Silva (2009) as principais atividades durante a visita envolvem no mínimo uma palestra, vídeo ou documentário educacional, uma descrição das instalações e um "passeio interno", além de programações educativas, como olimpíadas de ciências, minicursos, plantões de dúvidas (auxiliando os estudantes), visitas científicas monitoradas às exposições, capacitação para professores, entre outras. É neste ambiente que ocorre uma maior interação entre os alunos, seus colegas e os professores, provocando discussões e curiosidades acerca do exposto. 
Meira e Germano (2005) realizaram uma atividade, na qual parte da turma ficava no auditório assistindo a um vídeo educativo relacionado com a produção, distribuição e uso racional de energia ou alguma palestra, enquanto o restante participava da exposição no outro ambiente. Depois, a outra parte da turma dirigia-se ao ambiente de exposição enquanto o restante seguia para sala de vídeo. Considerando a vastidão dos conteúdos e o pouco tempo disponível, durante as exposições procurou-se seguir um rigoroso cronograma e divisão sistemática do tempo de modo que possibilitasse discutir sobre todos os experimentos. Tais exposições, além de incentivar questionamentos e respostas entre os estudantes também procuraram envolver os participantes em atividades lúdicas e divertidas. No entanto, também há experimentos apenas demonstrativos, outros expostos, ou seja, eram exposições onde os alunos apenas observavam. Ao final era realizada uma conversa sobre os conceitos científicos envolvidos nos mesmos. Segundo esses autores, no que se refere às escolas, essa forma de visitação é muito importante para despertar o interesse dos estudantes por assuntos de ciência e motivar estudos mais aprofundados daquilo que foi visto de forma rápida e informal durante a visitação.

Silva e Carneiro (2003) realizaram um estudo no museu de Anatomia Humana para verificar as formas como a exposição relacionava-se e comunicava-se com o visitante (atuação do público versus atuação dos monitores), observando a exposição, monitores, professores e alunos na hora da visita. A observação formal teve como meta identificar perguntas de interesse mais frequentes durante o momento da visitação, o percurso seguido pelos visitantes, o percurso sugerido pelos monitores, enfim, descrever como foi realizada a visita, principalmente no que tange à transmissão do conhecimento científico. Nesse museu, a atuação dos monitores consistia na principal forma de comunicação dentro do espaço expositivo, uma vez que as informações contidas nas etiquetas são restritas, sem apelo à participação dos visitantes.

Calvo e Stengler (2004) realizaram uma atividade em um museu de ciências, o qual apresenta uma simulação do sistema solar, exposições e diferentes módulos. As atividades que são desenvolvidas nesse espaço, especificamente, são as demonstrações: nelas os princípios científicos ou tecnológicos se transmitem através de experimentos realizados frente ao público, como um espetáculo. Os monitores vão expondo uma linha narrativa de experimentos para a realização dos quais vão solicitando voluntários e colaboradores dentre os presentes. Fazem-se perguntas que são aproveitadas para seguir sua linha argumental. Esta linha, ainda que não muito rigorosa, consegue a comunicação com o público. Além disso, são realizados acampamentos astronômicos, nos quais os alunos pernoitam no centro, participando de diversas atividades em torno dos conteúdos do museu e de observações astronômicas; salão de atos, aos domingos, onde realiza-se o cinema fórum, com a projeção de um filme de ficção científica e um posterior debate, uma maneira curiosa e divertida de familiarizar-se com a ciência que "intervém" no cinema; planetário, que conta com diferentes programas; e o turismo cósmico, que consiste na reprodução de três objetos diferentes do sistema solar (Marte, Júpiter e um cometa). 
Para um melhor aproveitamento, Calvo e Stengler (2004) propuseram a elaboração de um caderno de trabalho para o aluno, no qual, através de fichas, são apresentadas atividades para trabalhar antes, durante ou depois da visita. Além disso, estabeleceram rotas - por exemplo, a rota da água ou a rota ambiental. Nestas rotas, o corpo discente trabalha só determinados módulos, ainda que possa desfrutar de todo museu. Nenhum módulo integrante de uma mesma rota é similar a outro, para evitar um trabalho monótono. Os autores também elaboraram o guia para o professor de cada uma destas rotas. No trabalho realizado, os alunos foram organizados em pequenos grupos e cada um trabalhou em um módulo diferente: analisavam a informação oferecida, a qual foi adaptada a um nível concreto de educação primária e elaboraram uma atividade para realizar posteriormente em sala de aula com relação a dito módulo. Todo este trabalho, exposto depois em aula, desencadeou discussões nas quais surgiram valorações e contribuições sugestivas e interessantes.

Segundo Rojas (2007), os museus do Banco Central da Costa Rica se baseiam nas teorias da aprendizagem para oferecer diversas propostas tanto nas exibições como nos programas oferecidos ao público. Nestes programas é enviada à escola uma folha de pré-visita, com o objetivo de preparar os estudantes antes da sua chegada ao museu. Além disso, realiza-se uma visita, na qual se utiliza uma dinâmica de perguntas e respostas para promover a socialização do conhecimento e, os estudantes são motivados a observar e explorar manualmente os objetos da exibição, para reconhecer suas características, o material de que são feitos, o contexto no qual foram utilizados, entre outros aspectos.

Neste processo, os estudantes retomam os conhecimentos prévios, contrastando-os com os de seus colegas e com as novas informações obtidas da exibição, enriquecendo ou fortalecendo suas hipóteses ou eliminando-as/descartando-as. Trata-se então de contribuir para o desenvolvimento nos estudantes da observação crítica, da análise, da comparação e da dedução, bem como de outras habilidades. Para concluir o processo, oferece-se um roteiro, no qual os estudantes podem pôr em prática alguns dos conhecimentos aprendidos durante a visita. Os programas também oferecem folhetos didáticos nos quais se faz um resumo da informação trabalhada com os estudantes. Este material se constitui como uma das sugestões de pós-visita que são oferecidas ao docente para que, mediante atividades de investigação, sejam retomados em aula alguns conceitos aprendidos.

Segundo Meurer e Steffani (2009) essas atividades também podem ser oferecidas como objetos educacionais informatizados na forma de jogo - o jogo, além de abordar conteúdos, estimula o fator lúdico na aprendizagem. Assim, objetos dessa natureza atraem e divertem enquanto educam tanto crianças quanto adultos. E o jogo, que alia o conteúdo com o aspecto lúdico, revela-se capaz de despertar nos estudantes o interesse pela ciência e auxiliá-los na autoaprendizagem e na construção do conhecimento através da interação. 


\section{Oficinas e Módulos experimentais}

Além das atividades em ambientes informais já descritas, também pode-se destacar as oficinas e as exposições constituídas de módulos interativos e experimentais, elaboradas especificamente para demonstrar ou simular um fenômeno científico, por meio das quais os estudantes estabelecem exploração visual, auditiva e tátil. Consistem em um espaço de ensino e de aprendizagem como uma forma de levar a ciência ao conhecimento do público e estimular os sentidos e a percepção do visitante. As sensações provocadas durante o desenvolvimento das atividades buscam envolver o visitante emocional e afetivamente, por meio do estímulo à reflexão e ao interesse pelos assuntos abordados, privilegiando o aspecto lúdico, a interatividade, a participação, a experimentação, a criatividade e a abordagem construtivista na apropriação do conhecimento (Rocha, Lemos e Schall, 2010).

Imbernon et al. (2009) mostram que as atividades propostas durante a realização de oficinas permitem ao aluno o desenvolvimento de habilidades, visto que cabe a ele levantar hipóteses, proceder ao registro individual escrito e colocar esses registros aos outros alunos para elaboração de um registro coletivo negociado, através da expressão oral e da argumentação.

Segundo Pereira, Chinelli e Silva (2008); Rosalem, Silva e Peña (2008) e Lozada, Araújo e Guzzo (2006), esses módulos podem ser desenvolvidos através de uma exposição itinerante portátil -, possibilitando sua realização tanto no museu ou centro de ciências como nas escolas, a qual é apresentada por meio de atividades de maneira interativa, experimental e lúdica, tendo por objetivo proporcionar aos participantes a construção de conhecimentos, através do impacto das atividades experimentais com suas concepções, bem como despertar no sujeito o interesse e gosto pela ciência. Além de contribuir para a divulgação do conhecimento científico e tecnológico à população, essas atividades estimulam as escolas a utilizar a experimentação no ensino de ciências. Como exemplo, Stuchi e Bejarano (2003) desenvolveram uma atividade no âmbito do projeto Caminhão com Ciência da Universidade Estadual de Santa Cruz (UESC), projeto de divulgação científica em que se realizam exposições científicas itinerantes na região sul da Bahia. Essa atividade tem o objetivo de realizar experimentos, jogos, demonstrações e brincadeiras envolvendo aspectos diversos do conhecimento científico em exposições abertas ao público.

Nesse trabalho, os autores analisaram as interações sociais em torno do experimento Paradoxo Mecânico, com o objetivo de aprimorar o próprio experimento, aperfeiçoar a formação dos monitores para as exposições e avaliar sua capacidade de gerar situações que contribuam efetivamente para a alfabetização científica da população que visita as exposições. De acordo com 
os autores, ao alfabetizar cientificamente estão provendo instrumentos importantes para o ensino de ciências, por tentarem transformar o conhecimento em algo visível, palpável e atrativo, além de incentivar o interesse pela descoberta e análise do universo científico. Nesse contexto, assim como na maioria dos museus e centros espalhados pelo mundo, as pessoas podem mexer nos experimentos na medida do possível, colocando-os em funcionamento. Esse modelo, intitulado "hands on", é usado para estimular a curiosidade e a compreensão de conceitos científicos pelos visitantes. Além disso, é percebido que as atividades experimentais ocupam um papel relevante num ensino que busca proporcionar condições para que o sujeito construa seu conhecimento, colocando em conflito suas ideias prévias a partir do que observa em situações experimentais, contando com a mediação (uso da linguagem) dos outros (visitantes, monitores ou professores).

Costa e Dorrío (2010) destacam a importância da utilização das "atividades manipulativas" tanto na educação formal como na informal. Essas atividades de caráter manipulativo, fora do âmbito acadêmico, apresentam seu contexto natural nos museus e centros de ciências, caracterizando-se em um espaço de interação e cooperação entre os participantes, com tarefas próximas às que realizam os cientistas de forma orientada pelo professor, buscando que os estudantes nelas se envolvam de forma ativa, reflexiva e voluntária. Desta forma, a aprendizagem tende a se tornar mais significativa, pois suscita o interesse, promove uma atitude crítica, estimula a curiosidade pelo meio que nos rodeia e valoriza a interação entre as diversas áreas de conhecimento, com ações que na maioria dos casos têm resultados observáveis, sendo por isso possível compreender os fundamentos científicos por trás delas (Williams, 1990; Dorrío, 2006; Dorrío, 2008). Os alunos neste tipo de contextos informais experimentam excitação, interesse e motivação por aprender; recordam e usam conceitos, explicações, argumentos, modelos e fatos relacionados com a ciência; manipulam, exploram, praticam, observam fenômenos do mundo físico; reconhecem a ciência como uma forma de conhecimento; e participam coletivamente em processos de aprendizagem empregando as ferramentas e a linguagem adequada/apropriada.

Os autores explicitam que já realizam ações nesse sentido há alguns anos, através da rede "Hands-on Science", sendo que a metodologia pedagógica está baseada no "aprender fazendo". Para isso, realizam domínios web interativos, ferramentas de simulação virtual e laboratórios online de acesso livre, módulos educativos experimentais e material de apoio de diferentes níveis de complexidade. Esta rede produziu e difundiu livros de texto e relatórios, incluindo versões eletrônicas interativas, em diversos idiomas.

Segundo Dorrío e Vieites (2007), essas atividades podem servir como uma ferramenta de apoio ao trabalho que se realiza na sala de aula e apresentam importantes vantagens. Entre elas podemos destacar que: aumentam a compreensão de fenômenos científico-tecnológicos; desenvolvem atitudes mais favoráveis em relação à ciência; mostram a utilidade da ciência e da tecnologia; constituem uma importante fonte de motivação; incidem no caráter experimental da 
ciência e sua relação com a vida cotidiana; reforçam as habilidades criativas; estabelecem vínculos entre o formalismo científico e a realidade; permitem introduzir certa perspectiva histórica no processo de ensino e aprendizagem; e mostram a aplicabilidade do trabalho experimental.

Züge, Barros e Iramina (2006) realizaram uma atividade de ensino informal no museu Dinâmico Interdisciplinar da Universidade Estadual de Maringá (UEM) através de experimentos, interativos e demonstrativos, com explicação de monitores. Segundo os autores, o museu pode auxiliar o aluno a estabelecer a relação entre os conceitos espontâneos - originários de uma aprendizagem informal, relacionados às experiências do cotidiano - e os conceitos científicos apresentados pelos professores em sala, ou beneficiar-se mais tarde nas aulas lembrando a apresentação.

Segundo Delicio, Gandini, e Nunes (2007), o Museu de Ciência e Técnica da Escola de Minas da Universidade Federal de Ouro Preto oferece atividades interativas educativas que possibilitam aos diversos tipos de público deste museu a aproximação da ciência com a realidade do seu meio. Seu principal objetivo é desenvolver e oferecer um programa anual de atividades diversificadas, desenvolvidas para vários tipos de visitantes do museu, apresentando características específicas para cada tipo de público. As atividades oferecidas pelo museu são: um programa de atendimento ao público visitante, privilegiando o visitante-estudante e professores de todos os níveis de ensino, realizando atividades nos ambientes didáticos; a utilização do acervo do museu, que possibilita a interação entre o público visitante e principalmente estudantes com as peças e amostras deste acervo; oferecimento de cursos de formação continuada para professores, apresentando novas metodologias para o ensino de ciências; oferecimento de oficinas; emprego destes espaços educativos nas atividades de ensino dos cursos de graduação de diversas instituições de ensino superior; capacitação de funcionários, monitores e guias turísticos fazendo uso destes espaços educativos.

Quase todos os diversos setores do museu são contemplados com atividades práticas e experimentais que são desenvolvidas no laboratório didático de ensino de ciências (espaço multimídia e interativo), onde os visitantes podem manusear parte do acervo do museu. Essas atividades interativas são realizadas pelo público normalmente acompanhado de monitores. Assim, a partir deste tipo de ação está sendo possível mais do que transmitir conhecimento, despertar interesse pela ciência, incentivando a constante busca de informações, o que leva ao desenvolvimento integral dos indivíduos envolvidos neste processo. Outro aspecto relevante destas ações é o fato de que, por meio da dinamização na utilização do acervo do museu, há o fortalecimento desta instituição no sentido de promover a expansão e melhoria da qualidade de ensino das ciências, em todos os níveis, abrangendo tanto uma atuação de educação formal como informal no processo de ensino e aprendizagem, propiciando dessa forma a popularização da cultura científico-tecnológica. 
Rocha, Lemos e Schall (2007) descrevem uma atividade realizada em um museu, museu da vida - um departamento da Casa de Oswaldo Cruz - FIOCRUZ, que tem como missão divulgar e educar em ciência a partir de ações que valorizam a interatividade e a mediação em suas exposições. Deste modo, o museu oferece atividades ao público, abordando variados temas científicos e utilizando diferentes estratégias. As atividades, desenvolvidas nos seus espaços de visita envolvem aparatos interativos, oficinas, jogos, painéis expositivos, peças teatrais, entre outros recursos. A mediação cultural é um elemento importante para o atendimento, sendo privilegiada desde o momento da concepção e planejamento das atividades e, inclusive, na avaliação das mesmas. Por meio da mediação é possível potencializar as relações entre os conteúdos científicos específicos e o significado destes para os jovens, de modo que contribuam para sua aprendizagem, tendo o cuidado de não estabelecer dependência completa da mediação, aspecto mais característico da escola, principal contexto de educação formal. A mediação, mesmo sendo um tema em debate, para muitos elaboradores de exposições ainda representa a forma encontrada para proporcionar aprendizado quando são estabelecidos objetivos educacionais bem definidos para uma exposição.

De acordo com os autores, a expectativa do visitante em relação ao museu é um fator importante no processo de aprendizagem que estes espaços podem proporcionar. Conhecer o que o visitante sabe sobre o museu, o que espera encontrar na visita e como a mediação influencia no alcance destas expectativas parece ser um elemento de grande contribuição para a elaboração de novas exposições e atividades educativas. Outro fator importante é a comunicação com o público, a qual ocorre por meio de exposições que buscam motivá-lo e envolvê-lo emocional e intelectualmente.

\section{Outras reflexões}

Chinelli e Aguiar (2009), ao realizar uma análise das exposições de museus e centros de ciências cujas propostas educativas buscam a interatividade entre os equipamentos expostos e o público, constataram que a maioria dos equipamentos interativos foram considerados adequados à realização de experimentos, e uma minoria são demonstrações do tipo "aperte o botão", modelos e jogos. Quanto à experimentação, verificaram que parte significativa dos experimentos trazem painéis que orientam de maneira sucinta como usar o equipamento e que explicam brevemente os fenômenos que resultam da manipulação, e em outros não há informações sobre como manipular o equipamento exposto. Nestes, monitores orientaram a realização do experimento e forneceram explicações sobre os fenômenos observados. Outros ainda, não orientam sobre alguma forma de manipulá-los e mostram-se difíceis para a abordagem espontânea, sem que haja monitores para estimular e orientar a manipulação. Quanto ao envolvimento dos experimentos em algum contexto de significação (pesquisa científica, história do conhecimento, tecnologias, vida cotidiana, ou outro), perceberam que em poucos 
experimentos o monitor apresentou um contexto em que este se aplica e que fazem parte de exposições temáticas e estão relacionados ao tema. De maneira geral, quase que em sua totalidade, os experimentos não estavam relacionados a um contexto que thes conferisse significado, e são manipulados com curiosidade, mas sem reflexão.

No entanto, Stuchi e Ferreira (2003) apontam que existem trabalhos desenvolvidos nesses espaços de aprendizagem que não buscam a interatividade, os visitantes apenas assistem/visualizam a exposição dos experimentos e escutam a explicação do monitor, e a partir disso é proposto que os alunos assistam uma simulação de uma situação problema em um programa computacional, no qual deveriam utilizar os conceitos científicos aprendidos durante a exposição dos experimentos para a sua resolução.

Cabe destacar que a maioria dos museus e centros de ciências atuais utilizam tecnologias de ponta, com ênfase na participação "criativa" do visitante ao facilitar uma experiência definida por ele mesmo, escolhida entre várias opções. O grau de participação do visitante é intenso e ele possui independência para interagir com quaisquer aparatos. Segundo Soares (2010), o museu de ciências e tecnologia da PUCRS (MCT-PUCRS) é um exemplo, pois apresenta experimentos interativos, multimeios diversos, dioramas ${ }^{1}$, coleções científicas, aparelhos e materiais, laboratórios e grande número de outras atrações. Além disso, existem monitores disponíveis para orientar e fornecer explicações acerca dos inúmeros experimentos presentes no local. Neste sentido, tornou-se um espaço de grande riqueza e diversidade para complementar a educação científica desenvolvida nas escolas da região Sul do Brasil e para a popularização da ciência e tecnologia no contexto em que se insere.

\section{Considerações finais}

De maneira geral, podemos concluir que na maioria dos museus e centros de ciências são oferecidas atividades de caráter experimental interativo - sujeito e objeto - sob duas formas: equipamentos e experimentos do tipo "aperte o botão" e experimentos em que o visitante toca e participa da demonstração do fenômeno envolvido. Além disso, os monitores auxiliam o aluno a compreender o funcionamento do aparelho. As atividades no museu atraem, mobilizam e despertam o interesse no aluno porque não são impostas, mas resultam de uma alternativa do aprendiz (Carvalho e Arruda, 2008 e Carvalho, 2009). Segundo Freitas et al. (2010), esses espaços

\footnotetext{
${ }^{1}$ Diorama é um modo de apresentar uma vista realística de uma cena em um espaço compacto. A cena que pode ser uma paisagem, plantas, animais, eventos históricos, é pintada sobre uma tela de fundo curvo, de tal maneira que simulem um contorno real - cria uma ilusão de profundidade e de movimento, dando a impressão de tridimensionalidade.
} 
têm como foco central a temática dos fenômenos e conceitos científicos e a importância da comunicação entre o visitante e a exposição, quando está composta por equipamentos que proporcionam maior interatividade e também que visam aumentar a interação do sujeito com o objeto através do aprender fazendo. Assim, o visitante tem a oportunidade de construir conceitos científicos a partir do seu próprio conhecimento e interage com o mediador enquanto realiza as etapas das atividades práticas propostas.

Nesse sentido, quando institucionalizada, a educação extraescolar em ciências apresenta como objetivos: melhorar o nível de interesse pela ciência; aumentar o desempenho dos estudantes nas disciplinas relacionadas à ciência e matemática; suplementar a aprendizagem formal em sala de aula por causa de seus benefícios afetivos que geram ganhos cognitivos; ampliar e aperfeiçoar o nível de alfabetização científica da sociedade como um todo. Para Dori e Tal, 2000 apud Cazelli, 2000, no que diz respeito à dimensão que trata da aprendizagem que habilita indivíduos a se organizarem com o objetivo de solucionar questões coletivas, pode-se dizer que ela vem ao encontro de alguns dos atuais aspectos da função educativa dessas instituições.

Diante do exposto nesse artigo, fica evidente que as pesquisas na área de educação em ciências realizadas em ambientes informais de aprendizagem, como museus e centros de ciências, tornaram-se significativas. No entanto, apesar da frequência de artigos resultantes das pesquisas na área de educação em ciências direcionadas para a compreensão do tipo de aprendizagem que ocorre nos locais fora das escolas, nota-se na literatura um esforço para melhor fundamentar filosoficamente essa vertente da educação em ciências (Cazelli, 2000). Além disso, quando se procuram respostas específicas sobre aprendizagem, há muito mais suposições e teorias do que dados (Gaspar, 1993). Na opinião do autor citado, essa é uma situação que não o surpreende, pois museus e centros de ciências são instituições relativamente recentes, e o domínio da aprendizagem informal em ciências é ainda pouco explorado e pouco usado (Wellington, 2000 apud Soares, 2004). As teorias pedagógicas, desde as mais antigas propostas pelos filósofos gregos às mais recentes, têm sido sempre vinculadas à educação formal, ou seja, à escola. Só ultimamente é que se observa a procura de modelos e propostas metodológicas adequadas ao processo de ensino e aprendizagem que ocorre, ou pode ocorrer, nesses espaços (Gaspar, 1993).

Por fim, é preciso fazer reflexões em torno da nossa prática pedagógica, propondo alternativas mais motivadoras, eficazes e lúdicas. As metodologias para o ensino e a aprendizagem das ciências precisam estar voltadas à formação de habilidades fundamentais nos alunos, como: pesquisa, leitura crítica para que possam formar opiniões, argumentar e agir em diferentes situações, fazer escolhas conscientes, além de estarem preparados para o convívio social harmônico e cidadão. Não devem ser reduzidas a tópicos desenvolvidos em um conhecimento fragmentado, sem uma visão complexa da vida em todos os seus aspectos. Devem desenvolver a curiosidade e o gosto de aprender nos alunos, incentivando e possibilitando o 
questionamento, investigando, levantando hipóteses, avaliando resultados. Diante disso, torna-se necessário investir em diferentes ambientes de aprendizagem e atividades pedagógicas que ajudem a formar alunos mais criativos e reflexivos, capazes de entenderem que a aprendizagem escolar é uma ponte para a construção de outros conhecimentos.

Deste modo, não basta conceituar ou definir os objetivos de uma instituição educacional de caráter informal, é preciso entender e avaliar suas potencialidades, sua proposta pedagógica, e verificar que lá a aprendizagem existe; é preciso procurar entender melhor de que maneira esse processo se desenvolve e, talvez mais importante ainda, quais são os fatores que podem influenciar na aprendizagem que ocorre nesses ambientes, tais como, a preparação e realização da visita e das atividades; características dos módulos; as ideias dos visitantes; as estratégias de comunicação e a presença dos monitores (Chagas, 1993; Griffin, 1998; Gil e Lourenço, 1999; Cuesta, et al., 2000, 2002, 2003; Caldeira, Pina e Santos, 2003; Rennie, et al., 2003 apud Ribeiro, 2005). Sendo assim, em um próximo trabalho, será apresentada uma proposta de caráter metodológico que possa fornecer um referencial teórico a essas instituições, e que dê indicações válidas aos pontos básicos aqui destacados, a fim de oferecer estratégias com potencial educativo para que se tornem ambientes apropriados para a aprendizagem das ciências.

\section{Referências}

ASENSIO, M. El marco teórico del aprendizaje informal. IBER Didáctica de las Ciencias Sociales, Geografía e Historia, v. 27, p. 17- 40, 2001.

ASENSIO, M. Los autómatas de Hefesto o el procedimiento para crear seres procedimentales. IBER Didáctica de las Ciencias Sociales, Geografía e Historia, v. 2, p. 79-98, 1994.

ASENSIO, M. ; POL, E. Nuevos escenarios para la interpretación del Patrimonio: El desarrollo de programas públicos. Madrid: Departamento de psicología, Universidade Autónoma (mimeo), 1999.

ASENSIO, M.; POL, E. Nuevos Escenarios en Educación. Aprendizaje informal sobre el patrimonio, los museos y la ciudad. Buenos Aires: Aique, 2002.

BARZANO, M. Educação não-formal nas aulas de didática: uma experiência com a Licenciatura em Ciências Biológicas. VI Escola de Verão para Professores de Prática de Ensino de Biologia, Física, Química e Áreas Afins, p. 1- 9, 2003.

BENZAQUEN, J. F. A socialização para cooperação: uma análise de práticas de educação nãoformal. Estudos de Sociologia, Revista do Programa de Pós-Graduação em Sociologia da UFPE, v. 12, n. 1, p. 79-97, 2007. 
BOEKAERTS. M.; MINNAERT, A. Self-regulation with respect to informal learning. International Journal of Educational Research, v. 31, n. 6, p. 533-544, 1999.

CALDEIRA, M. H.; PINA, E. M.; SANTOS, M. C. Luz, Cor e Visão. Caderno do Professor. Coimbra: Exploratório - Centro de Ciência Viva, 2003.

CALVO, C. V.; STENGLER, E. Los Museos interactivos como recurso didáctico: El museo de las Ciencias y el Cosmos. Revista Electrónica de Enseñanza de las Ciencias, v. 3, n. 1, p. 1-18, 2004.

CARVALHO, M. A. Um estudo sobre a inserção de atividades em educação não formal na disciplina Metodologia e Prática do Ensino de Física da Universidade Estadual de Londrina. Dissertação de Mestrado: Universidade Estadual de Londrina, 2009, 136 p.

CARVALHO, M. A.; ARRUDA, S. M. A prática de ensino na licenciatura em Física da UEL em ambientes de educação não-formal: atividades no Museu de Ciência e Tecnologia de Londrina. VIII Congresso Nacional de Educação da PUCPR - EDUCERE e III Congresso Ibero-Americano sobre violências nas escolas - CIAVE, Curitiba: Editora Champagnat, v. 1, p. 1-11, 2008.

CAZELLI, S. Divulgação Científica em Espaços Não-Formais. XXIV Congresso da Sociedade de Zoológicos do Brasil, p. 1-10, 2000.

CAZELLI, S.; VERGARA, M. R. O passado e o presente das práticas de educação não formal na cidade do Rio de Janeiro I Encontro de História da Educação do Estado do Rio de Janeiro, Niterói - Rio de Janeiro, p. 1-15. CD-ROM do I EHEd - RJ, 2007.

CHAGAS, I. Aprendizagem não formal/formal das ciências. Relações entre os museus de ciência e as escolas. Revista de Educação, Lisboa, v. 3, n. 1, p. 51-59, 1993.

CHINELLI, M. V.; AGUIAR, L. E. V. Experimentos e contextos nas exposições interativas dos centros e museus de ciências. Investigações em Ensino de Ciências, v. 14, n. 3, p. 377-392, 2009.

COLINVAUX, D. Museus de ciências e psicologia: interatividade, experimentação e contexto. História, Ciências, Saúde - Manguinhos, v. 12 (suplemento), p. 79-91, 2005.

COLOMBO Jr., P. D.; AROCA, S. C.; SILVA, C. C. Educação em centros de ciências: visitas escolares ao observatório astronômico do CDCC/USP. Investigações em Ensino de Ciências, v. 14, n. 1, p. 25-36, 2009.

CORSINI, A. M. A.; ARAÚJO, E. S. N. N.. Feira de ciências como espaço não formal de ensino: um estudo com alunos e professores do ensino fundamental. VI Encontro Nacional de Pesquisa em Educação de Ciências - VI ENPEC, Florianópolis - SC, p. 1-10, 2007.

COSTA, M. F. M.; DORRÍO, B. V. Actividades manipulativas como herramienta didáctica en la educación científico-tecnológica. Revista Eureka sobre Enseñanza y Divulgación de las Ciencias, v. 7, n. 2, p. 462-472, 2010. 
CUESTA, M; DÍAZ, M. P.; ECheVARRÍA, I.; MORENTíN, M.; PÉREZ, C. Museos y centros de ciencia en el mundo. Alambique, v. 26, p. 67-71, 2000.

Cuesta, M.; DíAZ, M. P.; ECheVARRÍA, I.; MORentín, M.; PÉREZ, C. Centros Interactivos de Ciência: Su Papel en el Aprendizaje de la Física, en Aspectos Didácticos de Física y Química. (Física). ICE. Universidade de Zaragoza., 2002.

CUESTA, M.; DÍAZ, M. P.; ECheVARRÍA, I.; MORENTíN, M.; PÉREZ, C. Utilización del museo de ciências como recurso didáctico en educación social. Revista Psicodidáctica, v. 15, n. 16, p. 85-94, 2003.

DELICIO, M. P.; GANDINI, A. L.; NUNES, G. A. Museu: ferramenta de Ensino de Ciências. I Simpósio de Pesquisa em Ensino e História de Ciências da Terra e III Simpósio Nacional sobre Ensino de Geologia no Brasil, UNICAMP, Campinas-SP, p. 207-209, 2007.

DIAMOND, J. The behavior of family groups in science museuns. Curator, v. 29, n. 2, 1986.

DORRÍO, B. Research Interpretation at University. International Journal o Hands-on Science, v. 1, n. 1, p. 33-39, 2008.

DORRÍO, B. V. Museos interactivos na escola. Revista Galega de Educación, v. 35, p. 20-22, 2006.

DORRÍO, B. V.; VIEITES, A. R. Actividades manipulativas para el aprendizaje de la Física. Revista Iberoamericana de Educación, v. 42, n. 7, p. 1-15, 2007.

FARIA, M. L. A Função Social dos Museus. Conferência Internacional - A Cultura em Acção: impactos sociais e territoriais. Porto, 2001.

FERREIRA, H.; PINTO, M.; SALVADOR, P.; BOTELHO, A.; CHAGAS, I. Fomentar o gosto pelas Ciências Naturais. Integração de actividades de aprendizagem formal, não formal e informal. In M. T. Oliveira (Coord.) Actas do X Encontro Nacional de Educação em Ciências - Educação formal e não formal, p. 388-398, 2003. Lisboa: DEFCUL.

FREITAS, F.; MARTINS, I. P. Promover a aprendizagem das ciências no 10 CEB utilizando contextos de educação não formal. Enseñanza de las Ciencias, n. extra, VII Congreso, p. 1-4, 2005.

FREITAS, C. S.; RIBEIRO, F. A.; JUNIOR, G. I. O.; MESSEDER, J. C. Oficinas em museus de ciências: uma abordagem não-formal no ensino de química. XV Encontro Nacional de Ensino de Química (XV ENEQ) - Brasília, DF, Brasil, p. 1-9, 2010.

GASPAR, A. A Educação Formal e a Educação Informal em Ciências. Ciência e Público, Rio de Janeiro, v. 1, p. 171-183, 2002.

GASPAR, A. Museus e Centros de Ciências - conceituação e proposta de um referencial teórico. Tese se doutorado - Faculdade de Educação, Universidade de São Paulo, São Paulo, 1993. 
GASPAR, A. O Ensino Informal de Ciências: de sua viabilidade e interação com o Ensino Formal à concepção de um Centro de Ciências. Caderno Catarinense de Ensino de Física. Florianópolis, v. 9, n. 2, p. 157-163, 1992.

GERBER, B. L.; MAREK, E. A.; CAVALLO, A. M. L. Development of an informal learning opportunities assay. International Journal of Science Education, v. 23, n. 6, p. 569-583, 2001.

GIL, F. B.; LOURENÇO, M. Que ganhamos hoje em levar os nossos alunos a um Museu. Comunicar Ciência, Ministério da Educação - Departamento do Ensino Básico, v. 1, n. 3, p. 4 - 5, 1999.

GOHN, M. G. Educação não formal, participação da sociedade civil e estruturas colegiadas nas escolas. Revista Ensaio, Rio de Janeiro, v. 14, n. 50, p. 27-38, 2006.

GRIFFIN, J. Learning Sciences Trough Practical Experiences, in Museums. International Journal of Science Education, v. 20, n. 6, p. 655-663, 1998.

GUISASOLA, J.; AZCONA, R.; ETXANIX, M.; MUJIKA, E.; MORENTIN, M. Deseño de estrategias en la aprendizaje para las visitas escolares a los museos de ciencias. Revista Eureka sobre Enseñanza y Divulgación de las Ciencias, v. 2, n. 1, p. 19-32, 2005.

IMBERNON, R. A. L.; TOLEDO, M. C. M.; HONÓRIO, K. M.; TUFAILE, A. P. B.; VARGAS, R. R. S.; CAMPANA, P. T. C.; FALCONI, S.; INFANTE-MALACHIAS, M. E. Experimentação e interatividade (hands-on) no ensino de ciências: a prática na praxis pedagógica. Experiências em Ensino de Ciências, v. 4, n. 1, p.79-89, 2009.

LOZADA, C. O.; ARAÚJO, M. S. T.; GUZZO, M. M. Educar pela pesquisa e os museus de Ciências: um estudo de caso na Nanoaventura. X Encontro de Pesquisa em Ensino de Física - X EPEF, LondrinaPR, p. 1-12, 2006.

LUCAS, A. M. Scientific Literacy and Informal Learning. Studies in Science Education, v. 10, p. 1-36, 1983.

MARANDINO, M. Interfaces na relação museu-escola. Caderno Catarinense de Ensino de Física, v. 18, n. 1, p. 85-100, 2001.

MARANDINO, M.; SILVEIRA, R. V. M.; CHELINI, M. J.; FERNANDES, A. B.; RACHID, V.; MARTINS, L. C.; LOURENÇO, M. F.; FERNANDES, J. A.; FLORENTINO, H. A. A Educação não formal e divulgação científica: o que pensa quem faz? IV Encontro Nacional de Pesquisa em Ensino de Ciências ENPEC, Bauru, p. $1-13,2003$.

MEIRA, K. W.; GERMANO, M. G. Uma Experiência na Super Estação de Energia. XVI Simpósio Nacional de Ensino de Física - XVI SNEF - Rio de Janeiro, RJ, p. 1 - 4, 2005.

MEURER, Z; H.; STEFFANI, M. H. Objeto Educacional Astronomia: ferramenta de ensino em espaços de aprendizagem formais e informais. XVIII Simpósio Nacional de Ensino de Física - XVIII SNEF - Vitória, ES, p. 1 -7, 2009. 
OLIVEIRA, C. L.; MOURA, D. G. Projeto Trilhos Marinhos - uma abordagem de ambientes nãoformais de aprendizagem através da Metodologia de Projetos. Educação e Tecnologia., Belo Horizonte, v. 10, n. 2, p. 46-51, 2005.

PEREIRA, G. R.; CHINELLI, M. V.; SILVA, R. C. Inserção dos centros e museus de ciências na educação: estudo de caso do impacto de uma atividade museal itinerante. Ciências \& Cognição, v. 13, n. 3, p. 100-119, 2008.

PÉREZ, C. A.; MOLINÍ, A. M. V. Consideraciones generales sobre la alfabetización científica en los museos de la ciencia como espacios educativos no formales. Revista Electrónica de Enseñanza de las Ciencias, v. 3, n. 3, p. 1-26, 2004.

PINTO, V. M. M. Módulos interactivos de química em centros e museus de ciência. Dissertação de mestrado, Faculdade de Ciências da Universidade do Porto, 2007, 166p.

PRICE, S.; HEIN, G. More than a field trip: science programmes for elementary school groups at museums. International Journal of Science Education, v. 13, n. 5, p. 505-519, 1991.

RIBEIRO, M. E. C. Os museus e centros de ciência como ambientes de aprendizagem. Dissertação de Mestrado, Universidade do Minho, 2005, 241p.

ROCHA, M. Pequenos cientistas - grandes cidadãos: considerações sobre um programa de atendimento escolar no museu de ciências. Dissertação (Mestrado em Tecnologia) - Universidade Tecnológica Federal do Paraná, UTFPR, Curitiba, 2007, 178 p.

ROCHA, V.; LEMOS, E. S.; SCHALL, V. T. A contribuição do museu da vida para a educação não formal em saúde e ambiente: uma proposta de produção de indicadores para a elaboração de novas atividades educativas. X Reunión de la Red de Popularización de la Ciencia y la Tecnología en América Latina y el Caribe (RED POP - UNESCO) y IV Taller "Ciencia, Comunicación y Sociedad", San José, Costa Rica, p. 1-12, 2007.

ROCHA, V.; LEMOS, E. S.; SCHALL, V. T. Avaliação da aprendizagem sobre saúde em visita ao Museu da Vida. História, Ciências, Saúde - Manguinhos, Rio de Janeiro, v. 17, n. 2, p. 357-378, 2010.

ROJAS, F. C. Aprender en el museo: Los programas educativos de los Museos del Banco Central. IX Congreso Nacional de Ciencias: Exploraciones fuera y dentro del aula. Cartago, Costa Rica, p. 115, 2007.

ROSALEM, K. C.; SILVA, M. R.; PEÑA, A. F. V. Museu vivo: a ciência itinerante na região de Presidente Prudente. Segundo Encontro do Núcleo de Ensino de Presidente Prudente - ENNEP, ed. 1. p. 1-8, Universidade Estadual Paulista, São Paulo: Prograd UNESP., 2008.

SANTOS, L.; MATELA, V. Centros de ciência interactivos no ensino do 1 ํ ciclo do ensino básico - a terra e o sistema solar. Enseñanza de las Ciencias, no extra - VII Congresso, p. 1 - 5, 2005. 
SEMPER, R. Science museuns as environments for learning. Physics Today, 1990.

SILVA, M. R.; CARNEIRO, M. H. S. Popularização da ciência: análise de uma situação não formal de ensino. Reunião Anual da Associação Nacional de Pós-graduação e Pesquisa em Educação (ANPED), AGT: Educação e Comunicação, n. 16. FE/UNB, p. 1-16, 2003.

SOARES, C. T. S. O processo de significação da experiência museal: um estudo sobre o contexto pessoal de professores de ciências. Dissertação de Mestrado- Faculdade de Física, PUCRS, Porto Alegre-RS, 2010, 133p.

SOARES, A. H. M. A Química e a imagem da ciência e dos cientistas na banda desenhada: uma análise de livros de B. D. e de opiniões e interpretações de investigadores, professores de C. F. Q. e alunos do 3o ciclo. Dissertação de Mestrado, Universidade de Minho, Portugal, 2004, 313 p.

STUCHI, A. M.; BEJARANO, N. R. R. Alguns aspectos da interatividade possível em situações informais de ensino de ciências. IV Encontro Nacional de Pesquisa em Ensino de Ciências ENPEC, Bauru, p. 1-12, 2003.

STUCHI, A. M.; FERREIRA, N. C. Análise de uma Exposição Científica e Proposta de Intervenção. Revista Brasileira de Ensino de Física, v. 25, n. 2, p. 207-217, 2003.

TRILLA, J. La educación fuera de la escuela. Ambitos no formales y educación social. Ariel: Barcelona, 1993.

VIANA, E. C.; MONTEIRO, B. A. P.; MELO, J. S. A.; FRANÇA, F. M.; SILVA; J. O. Promovendo a Educação e a Divulgação em Ciências entre os Estudantes de Lavras por Meio de Ações no Museu de História Natural da UFLA. IV Congresso de Extensão da UFLA - CONEX, p. 1- 6, 2009.

VIEIRA, V.; BIANCONI, L.; DIAS, M. Espaços não-formais de ensino e o currículo de ciências. Ciência e Cultura, v. 57, n. 4, p. 21-23, 2005.

WILLIAMS, M. Understanding is both possible and amusing. Physics Education, v. 25, p. 253-257, 1990.

YÁÑEZ, J. L.; GARCÍA, C. M. El aprendizaje informal y su impacto sobre el desarrollo organizativo. Simposio "Estrategias de formación para el cambio organizacional", Barcelona, 2003.

ZÜGE, M.; BARROS, M.; IRAMINA, A. Objetivos das atividades experimentais no Museu Dinâmico Interdisciplinar - Aprendendo a ensinar Física I no Museu Dinâmico Interdisciplinar. IV Fórum de Extensão e Cultura da UEM: Perspectivas da Extenção Universitária e da Prestação de Serviços, Arq. Mundi, Maringá -PR, v. 10, n. 1, p. $274-276,2006$.

Ana Paula Sebastiany: Mestranda do Programa de Pós-Graduação em Educação em Ciências: Química da Vida e Saúde -UFRGS (bolsista CAPES). anapaulaslajeado@yahoo.com.br 
Michelle Camara Pizzato: Professora do Instituto Federal de Educação, Ciência e Tecnologia do Rio Grande do Sul. Porto Alegre, RS, Brasil. michelle.pizzato@poa.ifrs.edu.br José Cláudio Del Pino: Professor Associado do Instituto de Química da Universidade Federal do Rio Grande do Sul. delpinojc@yahoo.com.br

Tania Denise Miskinis Salgado: Professora Associada do Instituto de Química da Universidade Federal do Rio Grande do Sul. tania.salgado@ufrg.br 